\title{
Mosquito Repellent and Larvicidal Activities of Acalypha Indica Leaf Extracts
}

\section{Teklani PWNN, Perera BGK*}

Department of Chemistry, Faculty of Science, University of Colombo, Colombo-03, Sri Lanka

*Corresponding author: Perera BGK, Department of Chemistry, Faculty of Science, University of Colombo, Colombo-03, Sri Lanka, E-mail: gayani@sci.cmb.ac.lk

Received: March 20, 2017; Revised: March 31, 2017; Published: April 10, 2017

Copyright: (C2017 Perera BGK, et al. This is an open-access article distributed under the terms of the Creative Commons Attribution License, which permits unrestricted use, distribution, and reproduction in any medium, provided the original author and source are credited. The article has been previewed and authenticated by the Authors before sending the publication for print. The Journal, Editor and the Editorial Board are not entitled or liable to either justify or responsible for inaccurate and misleading data if any. It is the sole responsibility of the Author concerned.

Citation: Teklani PWNN, Perera BGK. Mosquito Repellent and Larvicidal Activities of Acalypha Indica Leaf Extracts. Int J Pharm Pharmacol 2017; 1: 107. doi: 10.31531/2581-3080.1000107

\begin{abstract}
In this study, mosquito repellent and larvicidal activities of leaf extracts of Acalypha indica were investigated against Aedes aegypti. Leaf extracts of Acalypha indica was prepared using maceration, Soxhlet extraction, sonication and steam distillation. Hexane, acetone, ethyl acetate, methanol and water were used as solvents. Mosquito repellent activity was investigated using static air repellency apparatus. The highest mosquito repellent activities were obtained by maceration in hexane and sonication in ethyl acetate and they vary from $60 \%$ to $20 \%$ in a period of three hours. In order to determine the larvicidal activity, mosquito larvae were treated with each plant extract and percentage mortality of mosquito larvae was obtained within $24 \mathrm{~h}$. Highest larvicidal activities (100\% mortality) were given by sonicated leaf extract in water $\left(100 \mathrm{mg} \mathrm{mL}^{-1}\right.$ ) and Soxhlet leaf extract in acetone (97 $\mathrm{mg}$ $\left.m L^{-1}\right)$.
\end{abstract}

Keywords: Acalypha indica, Aedes aegypti, Mosquito repellent, Larvicidal activity, GC-MS

\section{Introduction}

Acalypha indica is a weed which is widely distributed in Sri Lanka, India and many other countries and its English name is 'Indian acalypha' [1]. It has been reported that it is widely used for traditional medicine in several countries. It is used to treat different diseases such as bronchial asthma, skin disorders, constipation etc [2].

In many countries, mosquitoes are one of the major reasons for numerous human diseases. Teklani \& Perera. Int J Pharm Pharmacol
Some of the mosquito-borne diseases could be lethal. Dengue is such a mosquito borne viral infection which is caused by Aedes aegypti. According to the World Health Organization it has been reported that about 128 of countries are suffering from dengue and the number of people who get infected dengue has increased $[3]$.

Mainly there are three ways to control or prevent mosquito spread diseases. That is by 
destroying their breeding habitats, reducing the contact of mosquito vectors with humans and treating the disease with medicines. There are many synthetic insecticides and larvicides to kill or control the breeding of mosquitoes. However, using these products is now ineffective due to the resistance developed by the mosquitoes towards these agents. Additionally, there are side effects associated with these synthetic compounds. These include environmental pollution, adverse health effects to humans, etc [4]. Therefore, using natural mosquito repellents derived from plant extracts to control these pests may be an alternative and greener solution [5].

In this investigation leaf extracts of $A$. indica which was prepared from different extraction techniques and solvents are tested for their mosquito repellent activity and mosquito larvicidal activity. This was tested against Aedes aegypti to find out whether leaf extracts of $A$. indica can be used an alternative method to control the mosquito population in a country.

\section{Materials and Methods}

\section{Materials}

Hexane, ethyl acetate, acetone, methanol and water were obtained from Department of Chemistry, University of Colombo, Sri Lanka. All the solvents were industrial grade and were distilled prior to use.

\section{Instruments}

An Incubator Shaker (SI-600), Analytical balance (OHAUS PA313), Sonicator (GRANT XUB12), Rotary evaporator (Type N-N ser no10823000), GC-MS Spectrophotometer (Agilent 7890A, 5975C), Static air repellency apparatus were used during this research study.

\section{Plant Identification and Leaf Extract Preparation}

Acalypha indica which was collected from the areas of Western province of Sri Lanka was authenticated by the Department of Plant Sciences, University of Colombo, Sri Lanka. Acalypha indica plants were thoroughly washed with running water and then the leaves were air dried and were coarsely powdered using a domestic grinder. For the preparation of leaf extracts hexane, ethyl acetate, acetone, Teklani \& Perera. Int J Pharm Pharmacol methanol and water were used as solvents and maceration, Soxhlet extraction, sonication and steam distillation were used as the extraction techniques.

\section{Leaf Extracts Preparation Using Maceration}

Leaf materials were mixed with the solvent in the ratio of $1: 10$ and were shaken for $24 \mathrm{~h}$ at $37^{\circ} \mathrm{C}$ in a shaker set to a speed of $150 \mathrm{rpm}$. After the filtration of the mixture the solvent was evaporated using a rotary evaporator $\left(35^{\circ} \mathrm{C}\right)$ and then a nitrogen stream. [6].

\section{Leaf Extracts Preparation Using Soxhlet Extraction}

Leaf materials were added into the thimble of the Soxhlet extractor. Using a volume of 100 $\mathrm{mL}$ of the solvent the extraction was carried out for $4 \mathrm{~h}$ with each solvent. After the filtration of the mixture the solvent was evaporated using a rotary evaporator $\left(35^{\circ} \mathrm{C}\right)$ and then a nitrogen stream [6].

\section{Leaf Extracts Preparation Using Sonication}

Leaf materials were mixed with the solvent in the ratio of $1: 10$ and were placed in the ultrasonic bath for $2 \mathrm{~h}$ at a temperature of $35^{\circ} \mathrm{C}$. After the filtration of the mixture the solvent was evaporated using a rotary evaporator $\left(35^{\circ} \mathrm{C}\right)$ and then a nitrogen stream [6].

\section{Leaf Extracts Preparation Using Steam Distillation}

Fresh leaves of Acalypha indica were placed on the round bottom flask of the steam distillation apparatus. Then distilled water was added to the flask and it was heated to boil. The vapor generated was condensed and the resultant liquid was collected into a receiving flask. Essential oils were separated from the water phase using dichloromethane as the solvent. Anhydrous sodium sulphate was used to dry the extract completely [7].

\section{Mosquito Repellent Activity}

Mosquitoes (Aedes aegypti) were purchased from University of Kelaniya. The static air repellency apparatus was used to investigate the mosquito repellent activity against the leaf extracts of Acalypha indica. Selected plant extracts were diluted using acetone and 
solution with known concentrations such as $1 \%, 1.5 \%, 5.0 \%$ etc. (for $1 \%$ sample preparation $10 \mathrm{mg}$ of plant extract was dissolved in $1000 \mu \mathrm{L}$ of acetone) A volume of $1 \mathrm{~mL}$ of the plant extract (test sample) and acetone (control sample) were added separately into two filter papers (WhatmanTM $110 \mathrm{~mm}$ ). Both of them were kept on the two sides of the apparatus (Figure 1).

Then the number of mosquitoes in each side of the apparatus was counted at different time intervals and the percentage spatial repellencies were calculated using the following equation [8].

$$
\begin{gathered}
\text { Percentage spatial repellency (\%) } \\
=\left\{\frac{C-T}{\text { Tot }}\right\} \times 100 \%
\end{gathered}
$$

$\mathrm{C}=$ Number of mosquitoes in control side

$\mathrm{T}=$ Number of mosquitoes in test side

Tot $=$ Total number of mosquitoes

At least duplicates were carried out for all the plant extracts and triplicates were carried out for selected extracts with significant mosquito repellent activity.

\section{Larvicidal Activity}

A volume of $40.0 \mathrm{~mL}$ of distilled water was added into clean $100 \mathrm{~mL}$ beakers. Then to each beaker, eight mosquito larvae (Aedes aegypti) were added. A volume of $1 \mathrm{~mL}$ of plant extract was added to each beaker and the mortality of larvae was observed within $24 \mathrm{~h}$. A preliminary larvicidal screen was investigated with all the leaf extracts and triplicates were carried out for the extracts which showed a high mortality percentage. The percentage mortality was calculated using the following equation $[9,10]$.

Percentage mortality $(\%)=\frac{\mathrm{C}-\mathrm{T}}{\mathrm{C}} \times 100 \%$

$\mathrm{C}=$ Number of larvae survived in the control

$\mathrm{T}=$ Number of larvae survived in the test sample

GC-MS Analysis of the Macerated Leaf Extract in Hexane
Hexane, macerated plant sample which showed interesting biological activities including mosquito repellent activity was added into a vial. First, it was heated in a water bath at a temperature between 50 to $60^{\circ} \mathrm{C}$ for 20 mins. Then using a syringe, the volatile ingredients in the gas phase were collected and were injected to the GC-MS spectrophotometer (Head space injection). GC-MS trace was obtained.

\section{Results and Discussion}

\section{Mosquito Repellent Activity of the Leaf Extracts of Acalypha indica}

All the leaf extracts of Acalypha indica were tested for the mosquito repellent activity using the static air repellency apparatus. The results of the mosquito repellent assays are indicated in Table 1. All the plant extracts tested during this assay were kept at a concentration less than $5 \%$. This was to identify the plant extracts which show a considerable mosquito repellent activity even at very low concentrations. According to the results obtained during the mosquito repellent assays (Table 1), most of the leaf extracts of Acalypha indica displayed different levels of spatial repellency within the experimental time period. The extracts with higher spatial repellency during 2-3 $\mathrm{h}$ period were analyzed in triplicate trials whereas the other extracts were tested in duplicate trials.

As many plant, essential oils display mosquito repellent activity, the essential oil of Acalypha indica leaves obtained by steam distillation was also used during the mosquito repellent assays. Among the tested leaf extracts, several extracts of Acalypha indica have shown considerable percentage spatial repellencies against Aedes aegypti mosquitoes used in these assays. Two such extracts are the macerated leaf extract in hexane and the sonicated extract in ethyl acetate (Table 1). At 5\% concentration, both of the extracts show percentage spatial repellencies of $50 \%$ within the first two minutes and retain that capacity during the first hour. At the end of second and third hours, these extracts still manage to display a percentage spatial repellency of $20-30 \%$. For the macerated leaf extract in hexane, a similar mosquito repellent activity as observed for the $5 \%$ sample could be obtained even for the $1.7 \%$ sample (Figure 2). When consider the 
sonicated leaf extract in ethyl acetate, a slight overall improvement of the percentage spatial repellency was observed when the concentration of the sample was increased from $1.7 \%$ to $5 \%$ (Figure 3 ).

To investigate the constituents that could be responsible for the mosquito repellent activities, GC-MS analyses were also carried out for the macerated leaf extract in hexane. Previous studies have reported mosquito repellent activity of Soxhlet extracts in hexane for the leaves of Acalypha indica [11]. However, the novel findings of the mosquito repellent activity of macerated leaf extract in hexane and sonicated leaf extract in ethyl acetate could be practically more useful towards developing plant based mosquito repellent products. This is due to the ease of extraction of plant materials by maceration and sonication compared to the Soxhlet extraction. The Acalypha indica leaf extracts displaying mosquito repellent activity even at low concentrations such as $1.5-5 \%$ could be incorporated into mosquito repellent products. Since these are plant extracts, the percentage of the extract used in such products could be even higher than $5 \%$ as observed with currently commercially available natural mosquito repellent products.

It is important to note that the mosquito repellent Acalypha indica extracts were identified in this study by screening the extract against Aedes aegypti mosquitoes that are responsible in causing dengue. This further emphasizes the importance of the findings of the mosquito repellent assays carried out during this research.

\section{Mosquito Larvicidal Activity of the Leaf Extracts of Acalypha indica}

Mosquito larvicidal activity of the leaf extracts of Acalypha indica was investigated using Aedes aegypti mosquito larvae. The results of this assay are shown in Table 2. During the larvicidal assays six leaf extracts displayed significantly high larvicidal activity against Aedes aegypti larvae (75-100\%). Those include the Soxhlet extracts in ethyl acetate, acetone and water, the macerated extract in acetone and the sonicated extracts in methanol and water. Complete mosquito larvicidal activities were obtained from the leaf extracts sonicated in water and Soxhlet extracted in acetone. These extracts displayed $100 \%$ larvicidal activity at the tested concentrations of the extracts.

Previous studies which have been carried out in India have shown the mosquito larvicidal activity of Acalypha indca Soxhlet extracts in acetone and hexane against Aedes aegypti. Therefore, during this study, a few more novel plant extracts with mosquito larvicidal activity were identified and these can be used to control Aedes aegypti, which in turn will help to control or reduce dengue since it is one of the major mosquito borne diseases [11]. The newly identified extracts to possess mosquito larvicidal activity include Soxhlet and sonicated extracts of water, sonicated extract in methanol, macerated extract in acetone and Soxhlet extract in ethyl acetate.

The aqueous extracts obtained by sonicated and Soxhlet extraction resulted in $100 \%$ and $96 \%$ of larvicidal activity respectively.

Additionally, the other extracts newly characterized for their mosquito larvicidal activity; the Soxhlet extract in ethyl acetate, macerate extract in acetone and sonicated extract in methanol, all displayed excellent larvicidal activity at the tested concentrations. Even though macerated leaf extract in hexane indicated significant mosquito repellent activity, it does not behave as a good larvicide. This might due to the difference in the bioactive ingredients that result in the two different bioactivities.

When considering the sonicated extract in methanol which displayed a 92\% larvicidal activity at a concentration of $57 \mathrm{mgmL}^{-1}$, it could be considered as the most potent larvicidal extract. With a slight increase in the concentration of this extract it will be possible to achieve $100 \%$ larvicidal activity, whereas the other extracts needed higher concentrations of the extract than this to display $100 \%$ larvicidal activity. Therefore, this extract might be more suitable to use as a mosquito larvicide.

Even though both Soxhlet and sonicated extract in water gave good larvicide activity, the macerated leaf extract in water shows no larvicidal activity. This suggests that the compounds which are toxic for mosquito larvae 
are extracted into water only by the Soxhlet or sonicated extraction techniques and not by the maceration extraction technique.

\section{The GC-MS Analysis of the Macerated Leaf Extract in Hexane}

The macerated leaf extract in hexane was subjected to GC-MS analysis in order to investigate its chemical constituents that might have resulted in the mosquito repellent activity displayed by the extract. (The results obtained by the GC-MS analysis are shown in the Appendix Figure 1).

Previous GC-MS studies of the Soxhlet leaf extracts of Acalypha indica in hexane have reported the presence of compounds such as nhexadecanoic acid, octadecanoic acid, squaline etc. [11]. Similar or related compounds were detected in the macerated hexane extract during this study as well Table 3. When considering pinane, it is a derivative of pinene which is a monoterpene. Earlier studies for other plants regarding mosquito repellent activity have reported that monoterpenes could be used as mosquito repellents [12]. During these studies, it has been shown that some of the compounds listed in Table 3 have an effect on insect repellent activity [12].

\section{References}

1. Ediriweera, E. A review on medicinal uses of weeds in Sri Lanka. Trop Agric Res Ext 2010; 1: 11-16.

2. Jagatheeswari D, Deepa J, Sheik Jahabar Ali $\mathrm{H}$, et al. Acalypha indica L- an important medicinal plant: a review of its important traditional uses, and pharmacological properties. Int J Bot 2013; 3: 19-22.

3. Dengue and severe dengue. http://www.who.int/mediacentre/factsheets/ fs117/en/. 19 July, 2017.

4. Ranaweera SS. Mosquito-lavicidal activity of some Sri Lankan plants. J Natn Sci Coun Sri Lanka 1996; 24: 63-70.

5. Govindarajan M, Sivakumar R. Mosquito adulticidal and repellent activities of botanical extracts against malarial vector, Anopheles stephensi Liston (Diptera:

\section{Conclusion}

Highest mosquito repellent activities were displayed by macerated leaf extract in hexane and sonicated leaf extract in ethyl acetate. Macerated extract in hexane displayed a spatial repellency of $27-57 \%$ at $1.7 \%$ concentration and a spatial repellency of $30-65 \%$ at $5.0 \%$ concentration Sonicated extract in ethyl acetate displayed a spatial repellency of $17-47 \%$ at $1.5 \%$ concentration and $20-60 \%$ at $5.0 \%$ concentration. Highest larvicidal activities were displayed by Soxhlet extract in acetone and sonicated extract in water (100\% mortality).

Due to the mosquito repellent and larvicidal activities of Acalypha indica plant extracts, this plant can be used to control dengue as it is one of the major mosquito borne diseases in many countries.

\section{Acknowledgement}

Department of Chemistry, University of Colombo, Sri Lanka for providing all the necessary facilities to carry out the research work.

Culicidae) Asian Pac J Trop Med 2011; 4: 941-947.

6. Teklani PWNN, Perera BGK. The important biological activities and phytochemistry of Acalypha indica. Int $\mathrm{J}$ Res Pharm Sci 2016, 6: 30-35.

7. Boiling points and distillation. http://www.chem.wisc.edu/courses/342/Fall 2004/Distillation.pdf. 4 March, 2015.

8. Debboun M, Frances SP, Strickman DA. Insect Repellents Handbook, Second Edition.CRC Press, New York, 2014, 8384.

9. Gomathi R, Indrakumar I, Karpagam S. Larvicidal activity of Monstera adansonii plant extracts against Culex quinequefaciatus. J Pharmacogn Phytochem 2014; 3: 160-162.

10. Guidelines for laboratory and field testing of mosquito larvicides. http://apps.who.int/iris/bitstream/10665/691 01/1/WHO_CDS_WHOPES_GCDPP_200 5.13.pdf. 1 September, 2015. 
11. Vijaya Kumar S, Panagal M, John bastin TMM, et al. Mosquito Larvicidal, Oviposition deterrent and Repellent properties of Acalypha indica $\mathrm{L}$ extracts against Aedes aegypti, Anopheles stephensi, and Culex quinquefasciatus. Int $\mathrm{J}$ Med Biosci 2012; 1: 33-41.
12. Maharaj R, Maharaj V, Newmarch M, et al. Evaluation of selected South African ethnomedicinal plants as mosquito repellents against the Anopheles arabiensis mosquito in a rodent model. Malar J 2010; 9: 301 .

(a)

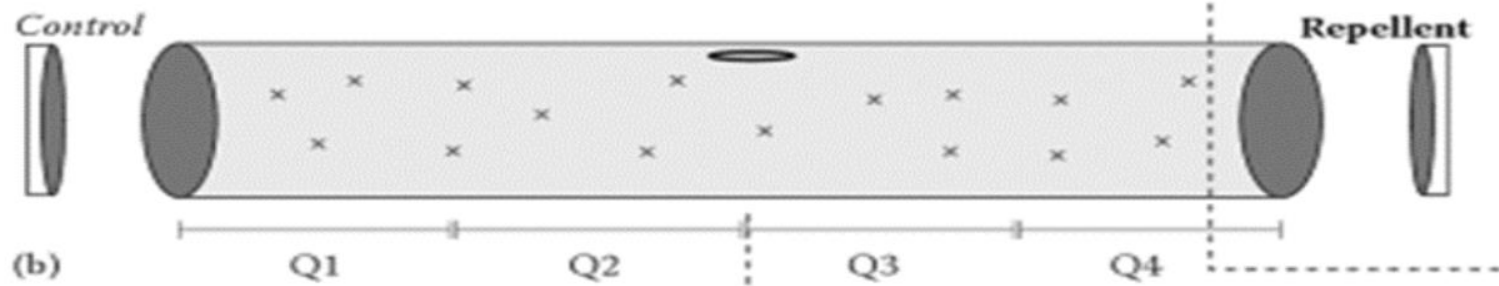

(b)

Q1

Q2

Q3

Q4

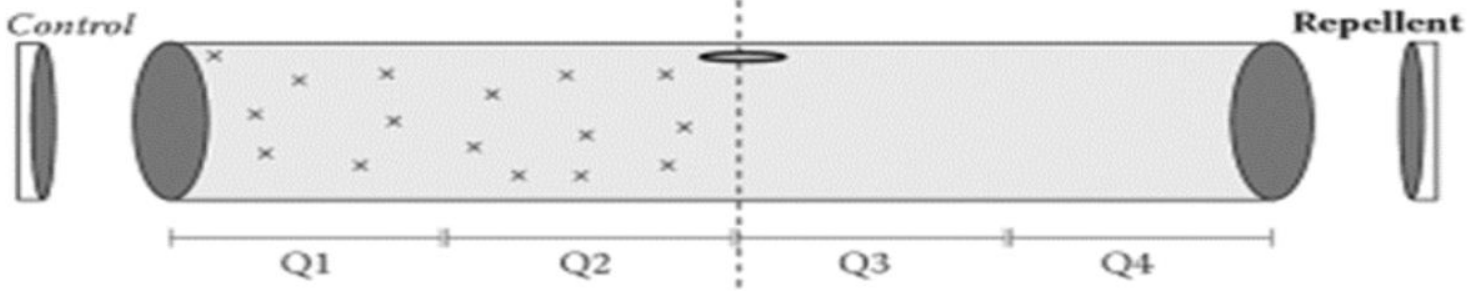

Figure 1: Static air repellency apparatus. (a) normal distribution of the mosquitoes (b) distribution of the mosquitoes in the presence of a repellent [8]

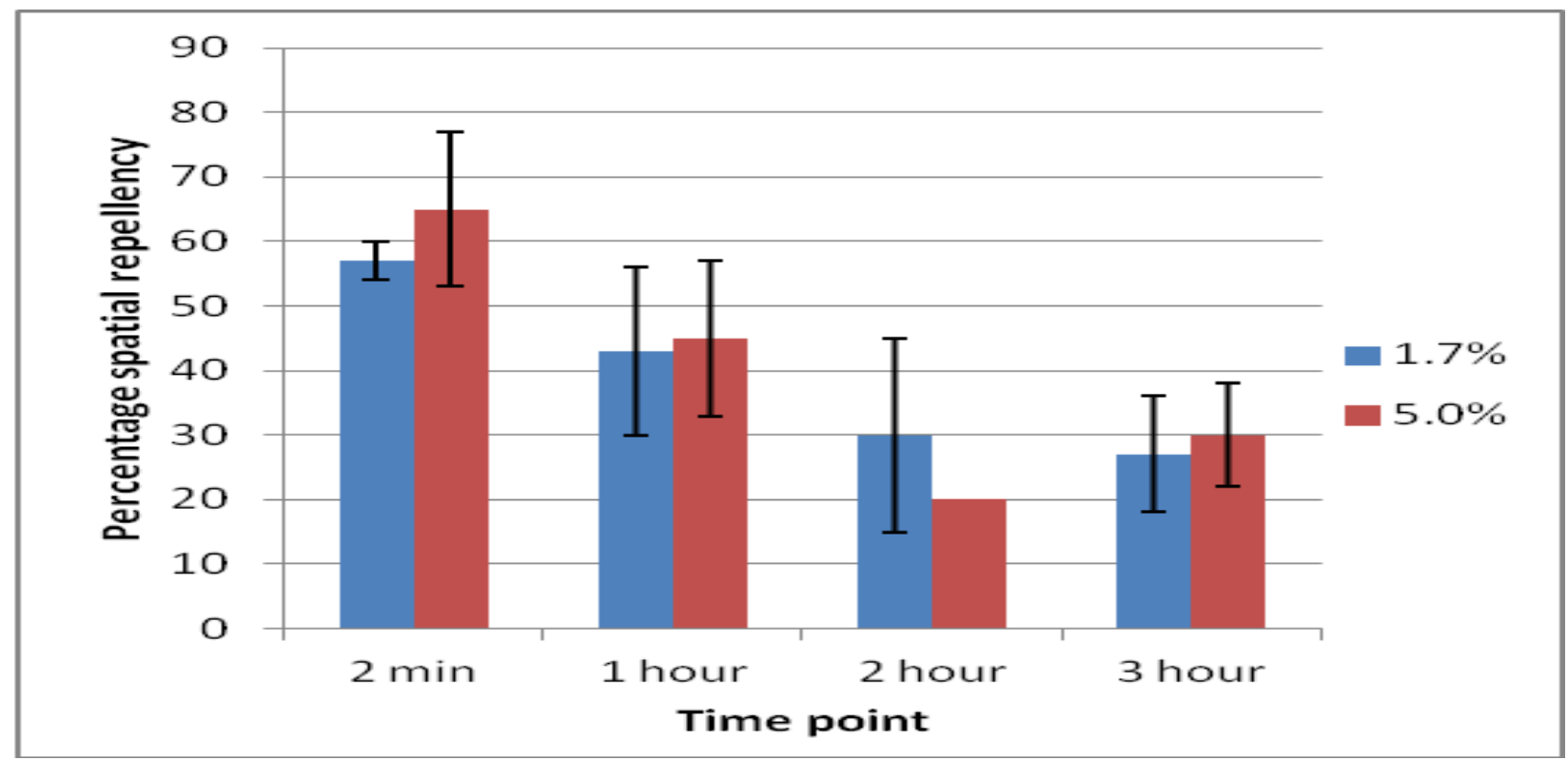

Figure 2: Percentage spatial repellency of the macerated leaf extract in hexane with time 


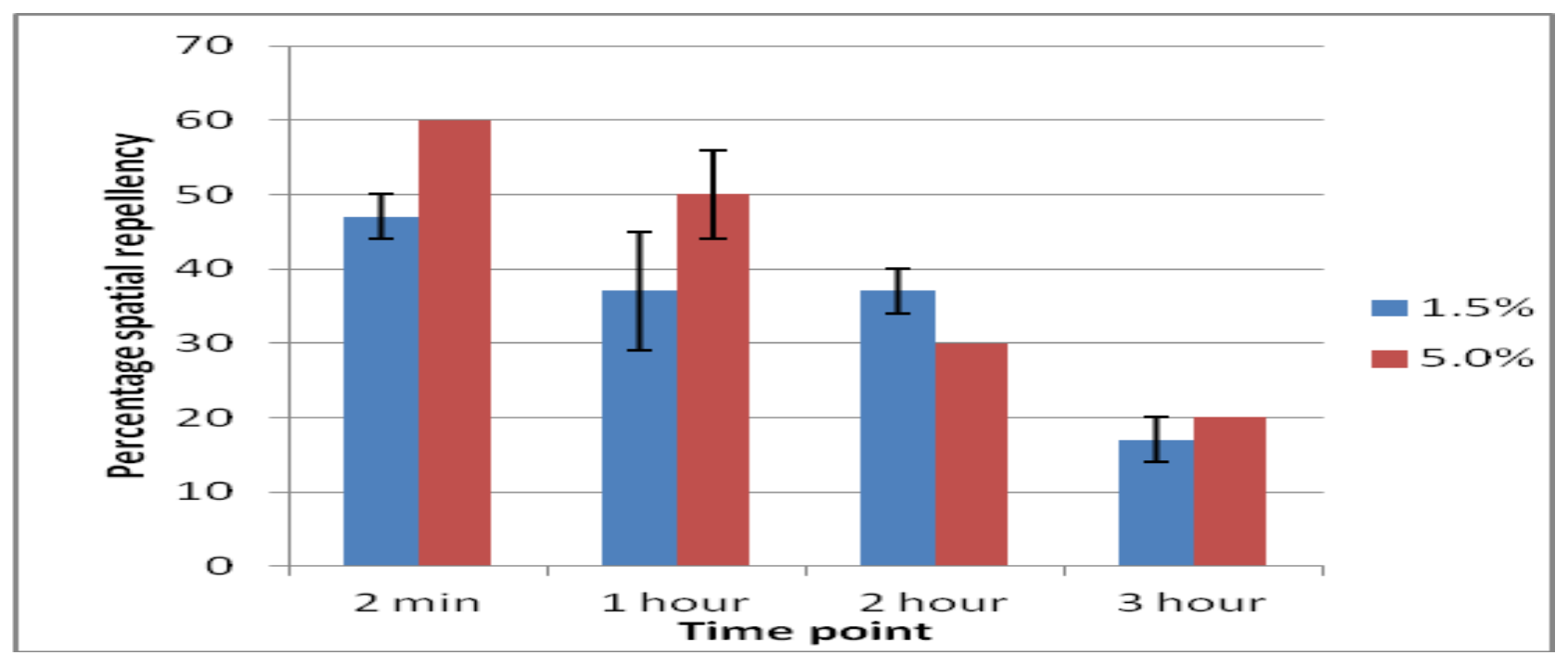

Figure 3: Percentage spatial repellency of the sonicated leaf extract in ethyl acetate with time

Table 1: Percentage spatial repellency of the leaf extracts of Acalypha indica during the mosquito repellent assays

\begin{tabular}{|c|c|c|c|c|c|c|}
\hline \multirow{2}{*}{$\begin{array}{l}\text { Solvent / } \\
\text { Sample }^{\mathrm{a}}\end{array}$} & \multirow{2}{*}{$\begin{array}{l}\text { Method of } \\
\text { extraction }^{\text {b }}\end{array}$} & \multicolumn{5}{|c|}{ Percentage spatial repellency at different time points (\%) } \\
\hline & & $\begin{array}{c}\text { Concentration } \\
(\%)\end{array}$ & $2 \min$ & $1^{\text {st }}$ hour & $2^{\text {nd }}$ hour & $3^{\text {rd }}$ hour \\
\hline \multirow{4}{*}{$\mathbf{H}$} & \multirow{2}{*}{ M } & 1.7 & $57 \pm 3$ & $43 \pm 13$ & $30 \pm 15$ & $27 \pm 9^{* *}$ \\
\hline & & 5.0 & $65 \pm 12$ & $45 \pm 12$ & $20 \pm 0$ & $30 \pm 8^{* *}$ \\
\hline & $\mathrm{S}$ & 1.5 & $45 \pm 4$ & $25 \pm 4$ & $35 \pm 4$ & $20 \pm 0$ \\
\hline & SN & 1.5 & $48 \pm 4$ & $26 \pm 6$ & $18 \pm 9$ & $10 \pm 0^{* *}$ \\
\hline \multirow{4}{*}{ EA } & $\mathrm{M}$ & 1.5 & $35 \pm 12$ & $25 \pm 4$ & $15 \pm 0$ & $11 \pm 1$ \\
\hline & $S$ & 1.5 & $13 \pm 5$ & $18 \pm 5$ & $18 \pm 5$ & $5 \pm 3^{* *}$ \\
\hline & \multirow{2}{*}{ SN } & 1.5 & $47 \pm 3$ & $37 \pm 8$ & $37 \pm 3$ & $17 \pm 3^{* *}$ \\
\hline & & 5.0 & $60 \pm 0$ & $50 \pm 6$ & $30 \pm 0$ & $20 \pm 0^{* *}$ \\
\hline \multirow{4}{*}{$\mathbf{A}$} & M & 2.0 & $20 \pm 0$ & $20 \pm 8$ & $35 \pm 4$ & $35 \pm 12$ \\
\hline & $\mathrm{S}$ & 1.5 & $40 \pm 6$ & $29 \pm 7$ & $17 \pm 12$ & $10 \pm 0^{* * *}$ \\
\hline & \multirow{2}{*}{ SN } & 1.5 & $39 \pm 1$ & $34 \pm 5$ & $23 \pm 9$ & $15 \pm 11^{* * *}$ \\
\hline & & 3.0 & $30 \pm 2$ & $16 \pm 6$ & $20 \pm 0$ & $10 \pm 3$ \\
\hline \multirow{3}{*}{ МеОН } & $\mathrm{M}$ & 1.5 & $25 \pm 2$ & $23 \pm 6$ & $25 \pm 4$ & $10 \pm 6$ \\
\hline & $\mathrm{S}$ & 1.5 & $30 \pm 8$ & $17 \pm 13$ & $17 \pm 3$ & $10 \pm 4$ \\
\hline & SN & 2.0 & $0 \pm 0$ & $25 \pm 7$ & $10 \pm 4$ & $0 \pm 0$ \\
\hline \multirow{3}{*}{$\mathbf{W}$} & $\mathrm{M}$ & 1.5 & $30 \pm 8$ & $32 \pm 1$ & $10 \pm 4$ & $15 \pm 4^{* * *}$ \\
\hline & $\mathrm{S}$ & 1.5 & $40 \pm 5$ & $33 \pm 3$ & $16 \pm 3$ & $16 \pm 7$ \\
\hline & $\mathrm{SN}$ & 1.5 & $5 \pm 4$ & $10 \pm 4$ & $10 \pm 4$ & $5 \pm 4$ \\
\hline Essential oil & SD & 1.0 & $60 \pm 1$ & $30 \pm 8$ & $20 \pm 0$ & $0 \pm 0$ \\
\hline
\end{tabular}

${ }^{* *}$ The extracts which were tested in triplicate trials. All the other extracts were tested in duplicate trials. ${ }^{a} \mathrm{H}-\mathrm{Hexane}, \mathrm{EA}-$ Ethyl acetate, A-Acetone, $\mathrm{MeOH}$ - Methanol, W-water

${ }^{b} M$ - Maceration, $S$ - Soxhlet extraction, $S N$ - Sonication, $S D$ - Steam distillation 
Table 2: Mosquito larvicidal activity of the leaf extracts of Acalypha indica

\begin{tabular}{|c|c|c|c|}
\hline Solvent / Sample ${ }^{a}$ & $\begin{array}{l}\text { Method of } \\
\text { extraction }\end{array}$ & $\begin{array}{l}\text { Concentration of the } \\
\text { extract }\left(\mathrm{mg} \mathrm{mL}^{-1}\right)\end{array}$ & $\begin{array}{c}\text { Percentage mortality } \\
(\%)\end{array}$ \\
\hline \multirow{3}{*}{$\mathbf{H}$} & $\mathrm{M}$ & 75 & 13 \\
\hline & $\mathrm{S}$ & 50 & 0 \\
\hline & SN & 54 & 25 \\
\hline \multirow{3}{*}{ EA } & $\mathrm{M}$ & 29 & 0 \\
\hline & $\mathrm{S}$ & 56 & $88 \pm 7^{*}$ \\
\hline & SN & 68 & $0 \pm 0^{*}$ \\
\hline \multirow{3}{*}{$\mathbf{A}$} & $\mathrm{M}$ & 77 & $75 \pm 12^{*}$ \\
\hline & $\mathrm{S}$ & 97 & $100 \pm 0^{*}$ \\
\hline & SN & 72 & 0 \\
\hline \multirow{3}{*}{$\mathrm{MeOH}$} & $\mathrm{M}$ & 53 & $27 \pm 9^{*}$ \\
\hline & $\mathrm{S}$ & 38 & 13 \\
\hline & SN & 57 & $92 \pm 8^{*}$ \\
\hline \multirow{3}{*}{$\mathbf{W}$} & $\mathrm{M}$ & 100 & 0 \\
\hline & $\mathrm{S}$ & 100 & $96 \pm 4^{*}$ \\
\hline & SN & 100 & $100 \pm 0^{*}$ \\
\hline Essential oil & SD & 24 & 0 \\
\hline
\end{tabular}

* The extracts which indicated the best mosquito repellent activity. These extracts were tested in triplicate. (the other extracts were tested in single trials)

${ }^{a} \mathrm{H}$ - Hexane, EA- Ethyl acetate, A- Acetone, $\mathrm{MeOH}$ - Methanol, W-water

${ }^{b} \mathrm{M}$ - Maceration, S- Soxhlet extraction, SN- Sonication, SD- Steam distillation

Table 3: Biochemical constituents found in the macerated Acalypha indica leaf extract in hexane GC-MS analysis

\begin{tabular}{|l|c|c|}
\hline \multicolumn{1}{|c|}{ Name of the compound } & $\mathbf{R}_{\mathbf{t}}(\mathbf{m i n})$ & Area under the curve (\%) \\
\hline 5-Methyl-2-phenylindolizine & 4.508 & 0.23 \\
\hline 2-Methyl-7-phenylindole & 4.508 & 0.23 \\
\hline 3- Methylphenol & 13.869 & 0.17 \\
\hline 2-(4-methylphenyl) indolizine & 14.041 & 0.01 \\
\hline 1-Hexadecanol & 24.163 & 0.06 \\
\hline Pinane & 34.268 & 3.98 \\
\hline 2,4-bis(1,1-dimethylethyl) phenol & 26.858 & 0.79 \\
\hline Octacosane & 28.615 & 0.11 \\
\hline Isocyclocitral & 34.886 & 0.03 \\
\hline Ethyl ester of hexadecanoic acid & 35.584 & 0.17 \\
\hline 2-Dimethylaminopyridine & 36.219 & 0.02 \\
\hline
\end{tabular}


This manuscript was peer-reviewed

Mode of Review: Single-blinded

Editor: Dr. Imran Kazmi

International Journal of Pharmaceutics and Pharmacology is an open access, peer reviewed journal published by Edwiser International.

Submit your valuable manuscript at-

editor.ijpp@edwiserinternational.com

submit.manuscript@edwiserinternational.com

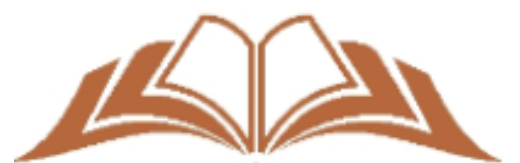

EDW $\mathrm{D}$ S E R
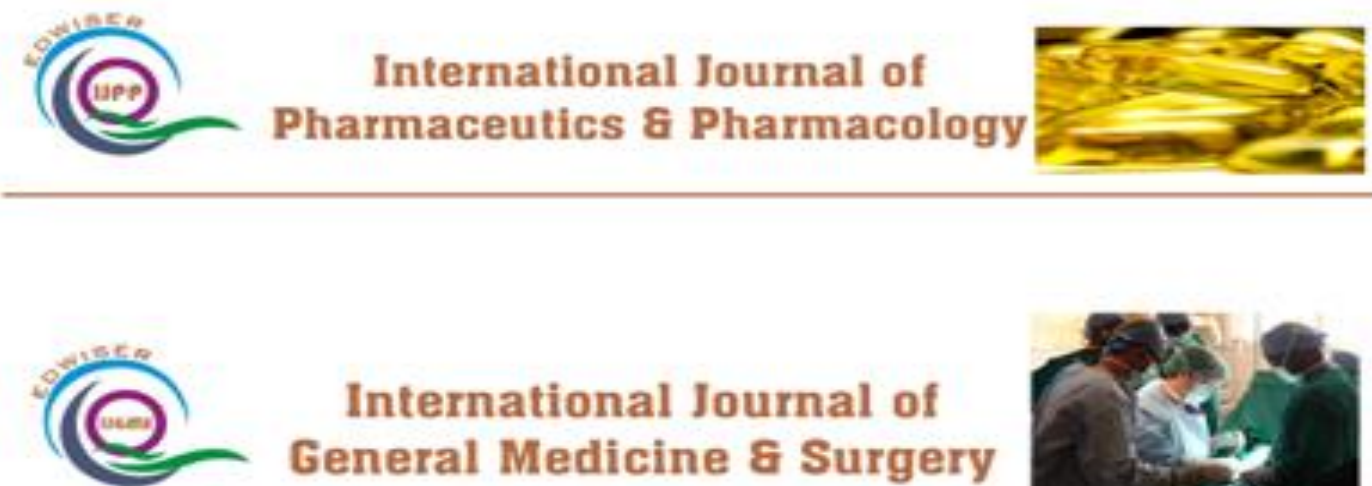

International Journal of General Medicine \& Surgery
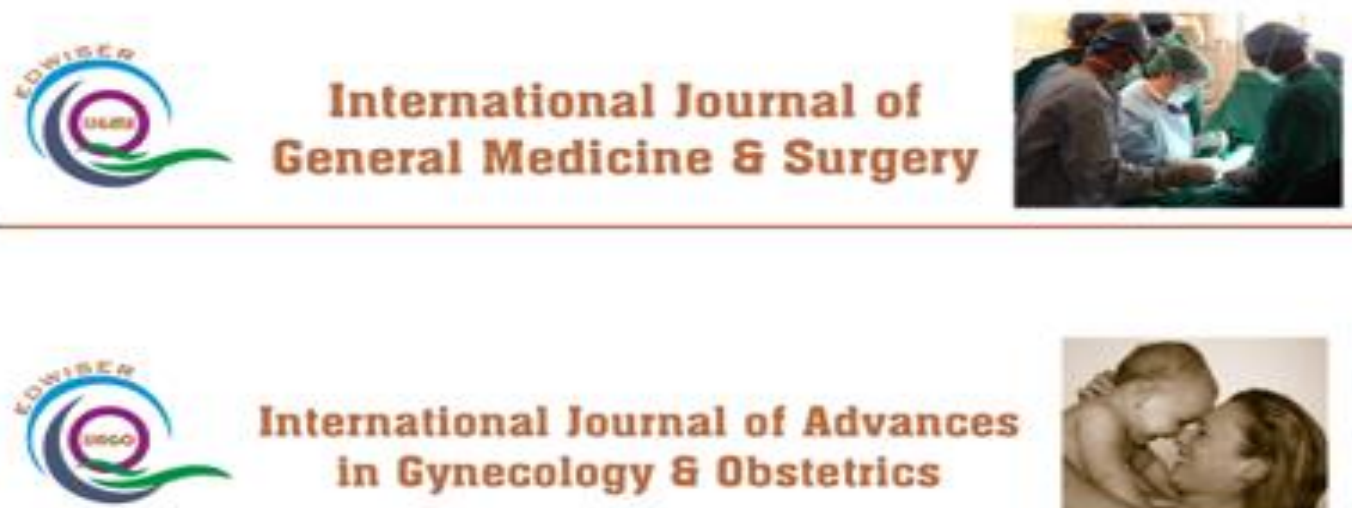

International Journal of Advances

in Gynecology \& Obstetrics
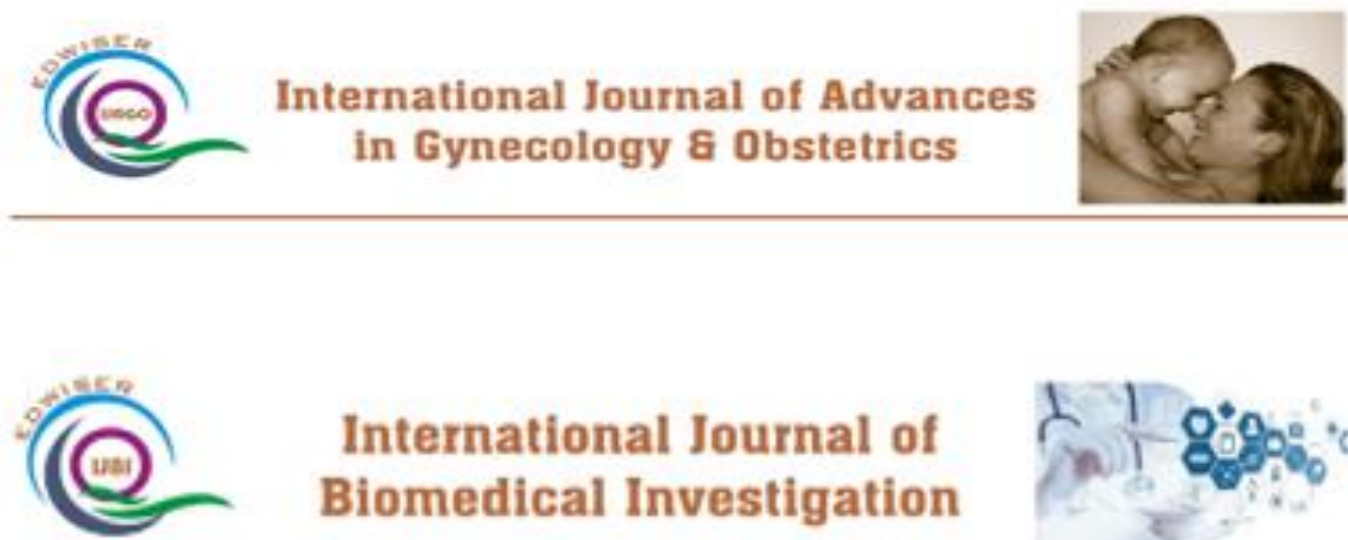

International Journal of Biomedical Investigation
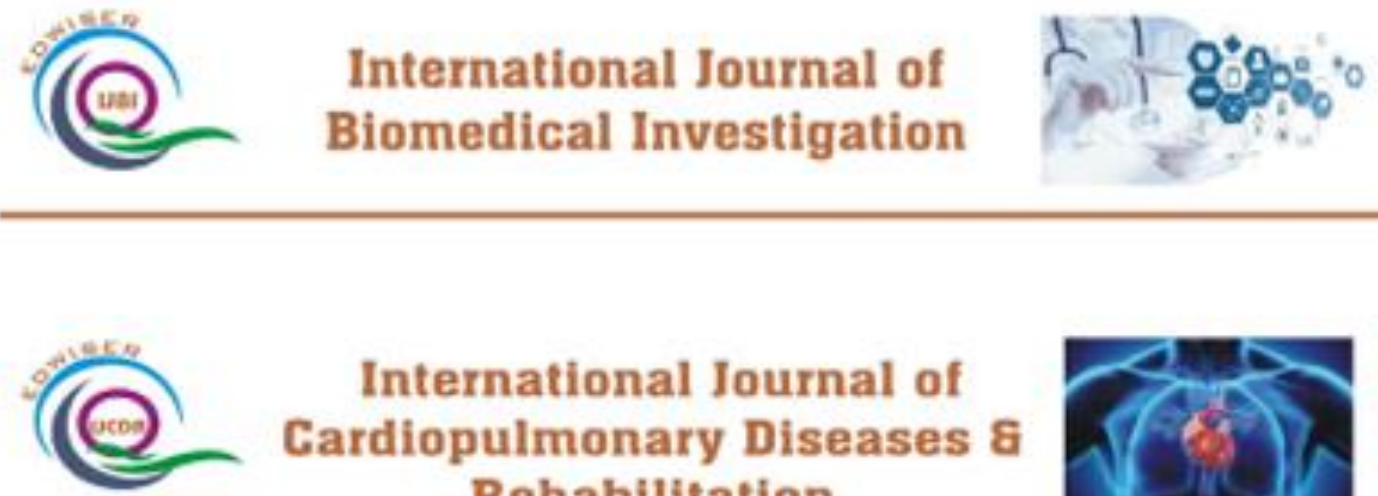

International Journal of Cardiopulmonary Diseases \& Rehabilitation

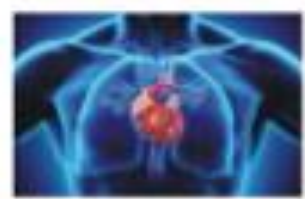

